\title{
Molecular regulation of telomerase activity in aging
}

\author{
Craig Nicholls ${ }^{1,3}, \mathrm{He} \mathrm{Li}^{1}$, Jian-Qiu Wang ${ }^{2}$, Jun-Ping Liu ${ }^{1,2,3,4} \bowtie$ \\ ${ }^{1}$ Molecular Signalling Laboratory, Murdoch Childrens Research Institute, Flemington Road, Parkville, Victoria 3052, Australia \\ 2 Institute of Aging Research, Hangzhou Normal University School of Medicine, Hangzhou 310036, China \\ 3 Department of Immunology, Monash University, Melbourne, Victoria 3004, Australia \\ ${ }^{4}$ Department of Genetics, University of Melbourne, Victoria 3052, Australia \\ $\triangle$ Correspondence: junping.liu@mcri.edu.au \\ Received August 20, 2011 Accepted August 30, 2011
}

\begin{abstract}
The process of aging is mitigated by the maintenance and repair of chromosome ends (telomeres), resulting in extended lifespan. This review examines the molecular mechanisms underlying the actions and regulation of the enzyme telomerase reverse transcriptase (TERT), which functions as the primary mechanism of telomere maintenance and regulates cellular life expectancy. Underpinning increased cell proliferation, telomerase is also a key factor in facilitating cancer cell immortalization. The review focuses on aspects of hormonal regulations of telomerase, and the intracellular pathways that converge to regulate telomerase activity with an emphasis on molecular interactions at protein and gene levels. In addition, the basic structure and function of two key telomerase enzyme components-the catalytic subunit TERT and the template RNA (TERC) are discussed briefly.
\end{abstract}

KEYWORDS telomerase, aging, telomerase reverse transcriptase (TERT)

\section{INTRODUCTION}

Rapidly dividing cells often suffer a short lifespan of only 20-40 population doublings, followed by cell senescence (aging) and apoptosis. Due to incomplete replication of the lagging strand some telomeric DNA is lost with each cell division, and this telomere erosion provides a mitotic clock, enabling a pre-determined number of cell divisions and facilitating replicative senescence once this limit is reached (Harley, 1991). Telomeres are also highly susceptible to genotoxic damage (Ayouaz et al., 2008; Rochette and Brash, 2010), and the accumulation of reactive oxygen species disrupts organelle membrane integrity and damages cellular enzymes and chromosomal DNA, including telomeres (Ramírez et al., 2003; Browner et al., 2004). Oncogeneinduced replicative stress may also cause telomere shortening by increasing the incidence of stalled replication forks at telomeres (Verdun and Karlseder, 2006; Martínez et al., 2009; Sfeir et al., 2009; McNees et al., 2010). Furthermore, deficiencies in telomere binding proteins may result in telomere uncapping and subsequent shortening (de Lange, 2009).

Dysfunctional telomeres trigger a DNA damage response through the activation of DNA-dependent protein kinase, ataxia-telangiectasia mutated (ATM), and ataxia telangiectasia and Rad3-related (ATR) (de Lange, 2009). Subsequent activation of the tumor suppressor p53 dependent pathway then induces cell cycle arrest. Uncapped telomeres can also undergo terminal deletions or end-to-end fusions via the nonhomologous end joining pathway (de Lange, 2009; Denchi, 2009). End-to-end fusions between sister chromatids (chromatid dicentrics) or different chromosomes (dicentric or multicentric chromosomes) can lead to breakage-fusionbridge (B-F-B) cycles (Murnane, 2010). In the absence of telomere repair B-F-B cycles underpin genome instability and trigger cellular aging and death.

Multiple studies have shown that telomere length in peripheral white blood cells inversely correlates with increasing age (Kimura et al., 2007; Njajou et al., 2007; Kimura et al., 2008; Njajou et al., 2009). Interestingly, in blood lymphocytes of 38 sex- and age-matched centenarians (at ages of 97-108), healthy individuals possessed significantly longer telomeres than their unhealthy counterparts (Terry et al., 2008). Furthermore, gene mutations in telomerase components underly the premature aging condition dyskeratosis congenital as well as idiopathic pulmonary fibrosis (Wong and 
Collins, 2003; Armanios, 2009; Calado and Young, 2009).

The telomerase enzyme is a specialized reverse transcriptase that maintains and extends telomeres through the de novo synthesis of telomeric DNA (Greider and Blackburn, 1985). Telomerase activity closely correlates with cellular differentiation, with decreased telomerase activity associated with increasingly differentiated cells (Sharma et al., 1995; Li et al., 2005). Somatic human cells generally possess levels of telomerase activity that are either undetectable or inadequate for telomere maintenance and subsequently succumb to replicative senescence (Allsopp et al., 1992). Therefore, cells that possess sufficient telomerase activity circumvent the replicative senescence or crisis states induced by telomere shortening and continue to proliferate indefinitely.

The presence of telomerase is strongly correlated with carcinogenesis, with approximately $85 \%-90 \%$ of human cancers having detectable telomerase activity (Shay and Bacchetti, 1997). Furthermore, inhibition of telomerase activity in telomerase-positive cancer cells results in cell death and tumor growth inhibition (Hahn et al., 1999; Herbert et al., 1999; Zhang et al., 1999; Cassar et al., 2008). This highlights the critical role of telomerase in facilitating and enabling cancer cell proliferation and has led to the development of several telomerase inhibitors that are currently being investigated as candidate anti-cancer drugs (reviewed in (Harley, 2008; Liu et al., 2010)).

\section{TELOMERASE DELAYS AGING AND PROMOTES LONGEVITY}

Telomerase is required for the normal development of the brain (Herrera et al., 1999), cardiovascular system (Ling et al., 2006; Grasselli et al., 2008) and ovary (Lee et al., 1998). However, solid evidence supporting a role for telomerase activation in longevity has been elusive until recently, with studies in both mice and humans providing significant insight. Activation of telomerase by constitutive over-expression of telomerase reverse transcriptase (TERT) in various tissues of mice resulted in an extension of maximum lifespan of up to 10\% compared to wild-type littermates (González-Suárez et al., 2005). The longer lifespan in these transgenic mice accompanies a low incidence of certain age-related degenerative diseases, though this is at the cost of a higher incidence of both induced and spontaneous tumors, causing increased mortality in the first year of life (González-Suárez et al., 2005).

To circumvent the increased susceptibility to cancer observed in mice over-expressing TERT, mice were engineered to also have enhanced expression of the tumor suppressors p53, p16, and p19ARF (Tomás-Loba et al., 2008). On the background of reinforced tumor suppressors, telomerase activation improves the fitness of epithelial barriers, particularly the skin and the intestine, and produces a systemic delay in aging accompanied by extension of the median life span (Tomás-Loba et al., 2008). The percentage of mice that reached the extremely old age of 3 years was significantly increased for the TERT-transgenic mice with increased tumor suppressor activity compared with the triply transgenic controls (tumor suppressors without TERT, 42\% vs $8 \%$ ), and the mean age of the upper longevity quartile was significantly increased (163 weeks vs 146 weeks) (TomásLoba et al., 2008). These studies indicate that activation of telomerase provides anti-aging activity in mammals.

In addition, recent studies in humans demonstrate that a common telomerase reverse transcriptase haplotype is associated with longer telomeres in Ashkenazi centenarians and their offspring, suggesting that telomerase is involved in lifespan determination for longevity (Atzmon et al., 2010). Changes in lifestyle such as a healthy diet and regular exercise have also been correlated with a modest increase in telomerase activity in human immune cells (Ornish et al., 2008). If telomerase inactivation or reactivation plays a direct causal role in aging and regeneration respectively has been convincingly demonstrated in experimental mice in vivo. Although loss of telomerase activity did not elicit a full spectrum of classical pathophysiological symptoms of aging, telomere shortening and genomic instability are associated with shortened lifespan and compromised capacity to respond to stresses such as wound healing and hematopoietic ablation (Rudolph et al., 1999). However, gene knocking in to rescue telomerase deficiency extends telomeres and reverses tissue degeneration in the aged telomerase-deficient mice (Jaskelioff et al., 2011). Furthermore, a hormonal receptor antagonist induces increased telomerase activation, extended lifespan and inhibited tumorigenesis in humans (see below).

\section{HORMONAL REGULATION OF TELOMERASE ACTIVITY AND LONGEVITY}

Sex and growth hormones are important regulators of cell growth and proliferation and studies have shown that estrogen is a key regulator in the positive regulation of telomerase. A lack of estrogen results in premature ovarian aging with follicular atresia, atrophic ovaries and infertility, and is modeled in the aromatase knockout (ArKO) mouse (Fisher et al., 1998; Britt et al., 2001; Britt et al., 2002). The critical involvement of estrogen in the ovary has stimulated clinical treatment of premature ovarian aging with estrogen (Tang and Sawers, 1989; Kalantaridou et al., 2006). In contrast to this beneficial outcome, recent studies indicate that high levels of estrogen are implicated in precipitating ovarian tumorigenesis in mouse models (Laviolette et al., 2010). Thus the presence of estrogen may be a double-edged sword, impairing premature ovarian aging though enhancing tumor formation. The precise mechanisms whereby estrogen elicits these effects on ovarian aging and tumorigenesis remains unclear, though complementary findings that estrogen stimulates 
telomerase in stem cells (Cha et al., 2008) and ovarian cancer cells (Misiti et al., 2000; Kimura et al., 2004) while estrogen deficiency induces telomerase inhibition and aging of the ovary and adrenal gland in mice (Bayne et al., 2008; Bayne et al., 2011) suggest that telomerase is a major downstream target of estrogen in aging and tumorigenesis in mammals.

Studies on postmenopausal women receiving hormone therapy for at least one year showed that estrogen is associated with longer telomeres in postmenopausal women, implicating telomere maintenance as an outcome of estrogen exposure (Lin et al., 2011). Thus, the link between estrogen deficiency, telomerase inhibition and telomere shortening may be part of the mechanisms of the overall aging process in estrogen responsive tissues.

The effects of estrogen on TERT expression may be partially mediated by an imperfect estrogen response element and an Sp1/ER half-site located in the distal region of the hTERT promoter (Misiti et al., 2000). However, estrogen also stimulates expression of c-Myc, a potent positive hTERT regulator (Kyo et al., 1999). Therefore, estrogen can upregulate hTERT expression through both cis and trans mechanisms and is likely a key regulator of telomerase activity in estrogen-responsive cancers.

Withdrawal of testosterone increases telomerase activity in normal rat and monkey prostate, suggesting androgens can negatively regulate telomerase (Meeker et al., 1996; Ravindranath et al., 2001). However, prostate cancer cells often have high levels of telomerase activity, even in the presence of androgens (Zhang et al., 1998; Wymenga et al., 2000). Furthermore, androgen deprivation inhibits telomerase activity in androgen-sensitive cancer cell lines, and androgenablation therapy is associated with the regression of prostate tumors (Soda et al., 2000). Androgens have also been shown to stimulate hTERT in prostate cancer cells, though this is likely via an indirect mechanism as there is a significant delay between androgen treatment and an increase in hTERT levels, and androgen cannot activate an hTERT promoter construct (Guo et al., 2003). Therefore, androgens can negatively regulate telomerase in normal cells, but enhance telomerase activity in cancer cells. This duality may be due to a mutation in the androgen receptor (T877A) that is commonly identified in prostate cancers, as cells expressing this mutant receptor were recently found not to down-regulate hTERT in the presence of androgen (Moehren et al., 2008).

Antagonizing growth hormone releasing hormone with the receptor antagonist MZ-5-156 alleviated premature aging and extended the lifespan of SAMP8 mice by eight weeks (Banks et al., 2010). In addition to this longevity, mice treated with MZ-5-156 exhibited a marked increase in telomerase activity in multiple tissues while simultaneously experiencing a decreased incidence of tumor formation (Banks et al., 2010). Thus it is possible that telomerase activation stimulated by MZ-5-156 treatment is at least in part responsible for the anti-aging effect of MZ-5-156, facilitating maintenance of telomere length and genome stability. This enhanced stability could explain the reduced incidence of tumors in these treated mice (10\% to $1.7 \%)$, despite the common association of telomerase activation with carcinogenesis. However, it is noteworthy that MZ-5-156 has also been shown to inhibit telomerase activity in cancer by the same laboratory (Kiaris and Schally, 1999). The mechanisms underlying the apparent opposing effects of MZ-5-156 on telomerase regulation are not yet known. It is possible though that additional molecules are involved in switching MZ-5-156 regulation of telomerase structure and function from stimulation in several normal tissues to inhibition in cancer.

\section{STRUCTURE AND FUNCTION OF THE TELOMERASE ENZYME}

The telomerase holoenzyme is a ribonucleoprotein complex that consists of several proteins and an RNA moiety that together function as a specialized reverse transcriptase (Greider and Blackburn, 1987). While the entire telomerase holoenzyme is estimated to have a large molecular mass exceeding $500 \mathrm{kDa}$, the core components required for enzymatic activity in mammals are the catalytic subunit TERT, dyskerin (DKC1) and the RNA template TERC (Cohen et al., 2007). DKC1 and TERC are ubiquitously expressed in both cancerous and normal cells alike, while TERT is only expressed in cells possessing telomerase activity suggesting that it is the rate-limiting component of the enzyme (Feng et al., 1995; Heiss et al., 1998). In support of this, ectopic expression of TERT is sufficient to produce telomerase activity in otherwise telomerase negative cells (Counter et al., 1998). As a result, much focus has been concentrated on the regulation and action of TERT.

\section{Structure and function of TERT}

While a crystal structure for full-length human TERT is yet to be solved, current working models define four distinct domains based on function (Collins, 2006). These are: the telomerase essential $\mathrm{N}$-terminal (TEN) domain; the TERT RNA-binding (TRB) domain; the reverse transcriptase (RT) domain; and the TERT C-terminal extension (CTE) domain (Fig. 1). These regions are all required for the telomere lengthening function of telomerase.

The TEN domain is highly conserved amongst vertebrates and contains several nucleic acid binding motifs (Xia et al., 2000). Determination of the structure of the TEN domain from T. thermophilia TERT has revealed a specific interaction with telomeric DNA, as well as a non-specific RNA binding site (Jacobs et al., 2006). Moreover, mutations to several $\mathrm{N}$ terminal residues in both $S$. cerevisiae and human TERT do not affect the catalytic activity of telomerase in vitro, but abolish in vivo telomere lengthening (Friedman and Cech, 1999; Armbruster et al., 2001). This area has been termed the 

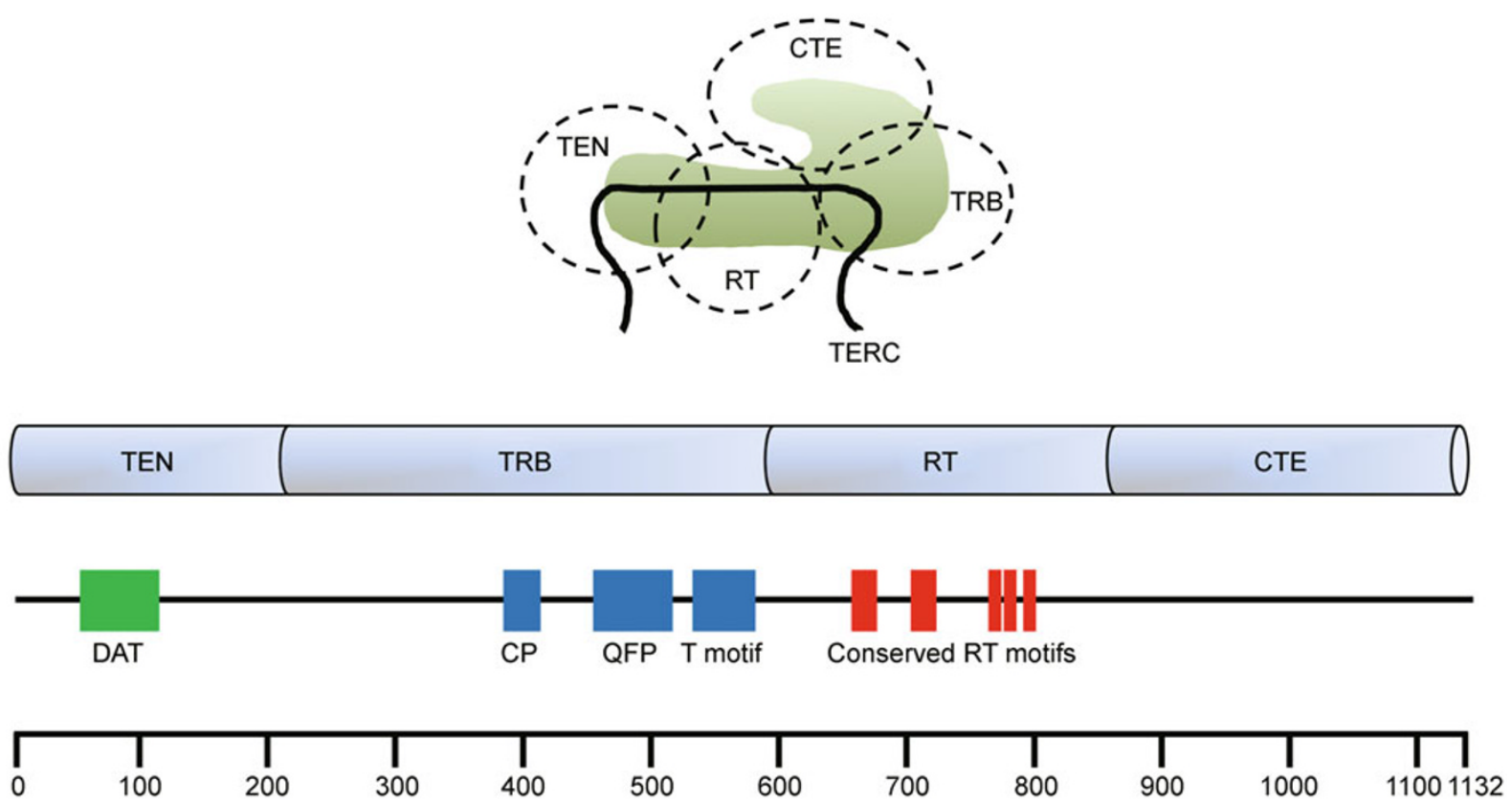

Figure 1. The structure of human telomerase reverse transcriptase (hTERT). Human TERT contains four key domains: the telomerase essential N-terminal (TEN) domain; the TERT RNA binding (TRB) domain; the reverse transcriptase (RT) domain and the C-terminal extension (CTE) domain. The TEN domain is important for appropriate action of telomerase at the telomere, as mutations in the DAT (dissociates activities of telomerase; green) region abolish in vivo telomere lengthening but not catalytic activity. The TRB domain contains several conserved RNA binding sequences (blue), including the telomerase-specific T motif, that are required for binding of TERC. The RT domain contains five conserved reverse transcriptase motifs (red) that are responsible for the catalytic activity of the enzyme. The CTE domain participates in numerous protein-protein interactions, and regulates enzyme processivity and localization.

DAT region, for 'dissociates activities of telomerase.' An additional study has identified a role for the DAT region in the recruitment of other key proteins of the telomerase holoenzyme (Friedman and Cech, 1999). Taken together, these findings demonstrate a critical role for the TEN domain in facilitating the assembly of an active telomerase complex at the telomere.

The TRB domain was identified by assessing the ability of $T$. thermophilia TERT harboring mutations to various conserved amino acids to bind TERC (Bryan et al., 2000). Truncation analysis confirmed that this domain extends from the N-terminal to the central region of hTERT, with a specific requirement for the $T$ motif located between amino-acid residues 566-593 (Bachand and Autexier, 2001; Lai et al., 2001). The recently solved crystal structure for full-length $T$. castaneum TERT demonstrates that the TRB domain positions TERC within the active site and also influences enzyme processivity (Gillis et al., 2008; Mitchell et al., 2010).

The RT domain contains classic conserved reverse transcriptase motifs and serves as the catalytic core of the enzyme (Nakamura et al., 1997). Mutation of residues within these motifs dramatically reduces or abolishes catalytic activity, though the interaction with the telomerase RNA template is unaffected (Bryan et al., 2000; Lai et al., 2001).
The CTE domain is involved in a number of telomerasespecific roles despite being weakly conserved across species (Kelleher et al., 2002). This domain influences the processivity of both human and $S$. cerevisiae TERT, similar to the manner in which human immunodeficiency virus type 1 reverse transcriptase processivity is influenced by its Cterminal region (Peng et al., 2001; Huard et al., 2003). Interestingly, the CTE domain is not required for in vitro catalytic activity of telomerase, though it is essential for in vivo lengthening of telomeres (Banik et al., 2002). Furthermore, binding sites for 14-3-3 proteins and CRM1 are located within the CTE domain and influence hTERT localization (Seimiya et al., 2000). Thus the CTE domain is required for ensuring the appropriate localization and efficient action of telomerase.

\section{Structure and function of the telomerase RNA component}

The human telomerase RNA component is 451 nucleotides in length and functions as a template that directs the addition of new telomeric repeats to the $3^{\prime}$ end of telomeres (Feng et al., 1995; Autexier et al., 1996). Though the primary sequence of TERC varies widely amongst organisms and cannot be aligned, conserved secondary structural elements do persist. 
Two of these elements are critical for the interaction with TERT and subsequent telomerase activity: the template harboring pseudoknot domain and the stem-loop CR4/CR5 domain (Chen et al., 2000). The discovery of a variety of disease-associated mutations in these key domains underscores their importance in the proper function of hTERC (Theimer and Feigon, 2006).

An hTERT-independent functional interaction exists between hTERC, Ku70/80 and hnRNP A1, which enhances phosphorylation of hnRNP A1 by DNA-PK (Ting et al., 2005; Ting et al., 2009). Studies have demonstrated that hnRNP A1 positively regulates both telomerase activity and telomere length, and it has been further shown that both telomeric DNA and hTERC can be bound by hnRNP A1 (LaBranche et al., 1998; Dallaire et al., 2000; Fiset and Chabot, 2001; Zhang et al., 2006). Therefore, hTERC may contribute to telomere maintenance independently of its direct role as a component of the telomerase enzyme by functioning as a scaffold that facilitates interactions among other factors that regulate telomere homeostasis. Furthermore, as TERC is expressed in the vast majority of mammalian cells independently of telomerase activity, it is possible that it possesses additional as yet uncharacterized telomere-independent functions.

\section{MECHANISMS OF TELOMERASE ACTION}

Telomerase extends chromosomes by binding to the terminal end of the telomeric 3' G-rich overhang and adding TTAGGG repeats. The telomerase reaction cycle is shown in Fig. 2 and consists of three distinct steps: substrate recognition and binding, elongation by addition of a single TTAGGG sequence and finally translocation to repeat the process or dissociation from the telomere.

Telomeres exist in at least two different conformational states: an 'open' state that facilitates telomere lengthening by allowing telomerase access to the chromosome end, and a 'closed' state that blocks telomerase action (Teixeira et al., 2004) (Fig. 3). Shorter telomeres adopt an open configuration, while the greater availability of binding sites for TRF1 and POT1 on longer telomeres facilitates the formation of a closed configuration (Loayza and De Lange, 2003). In this way, telomerase can be efficiently directed to the shortest telomeres within a cell, while sufficiently long telomeres do not undergo any inappropriate lengthening. However, this model is complicated by the observation that POT1 can, in conjunction with TPP1, recruit telomerase and enhance the extension of telomeres (Xin et al., 2007). Therefore additional elements are likely to play a role in directing the access of telomerase to telomeres.

Several lines of evidence have given rise to the hypothesis that telomerase also possesses telomere length and maintenance-independent functions. Increased telomerase activity in mice can promote tumorigenesis even in the absence of proliferation-restrictive telomere length (González-Suárez et al., 2001). Similarly, C-terminally tagged hTERT is unable

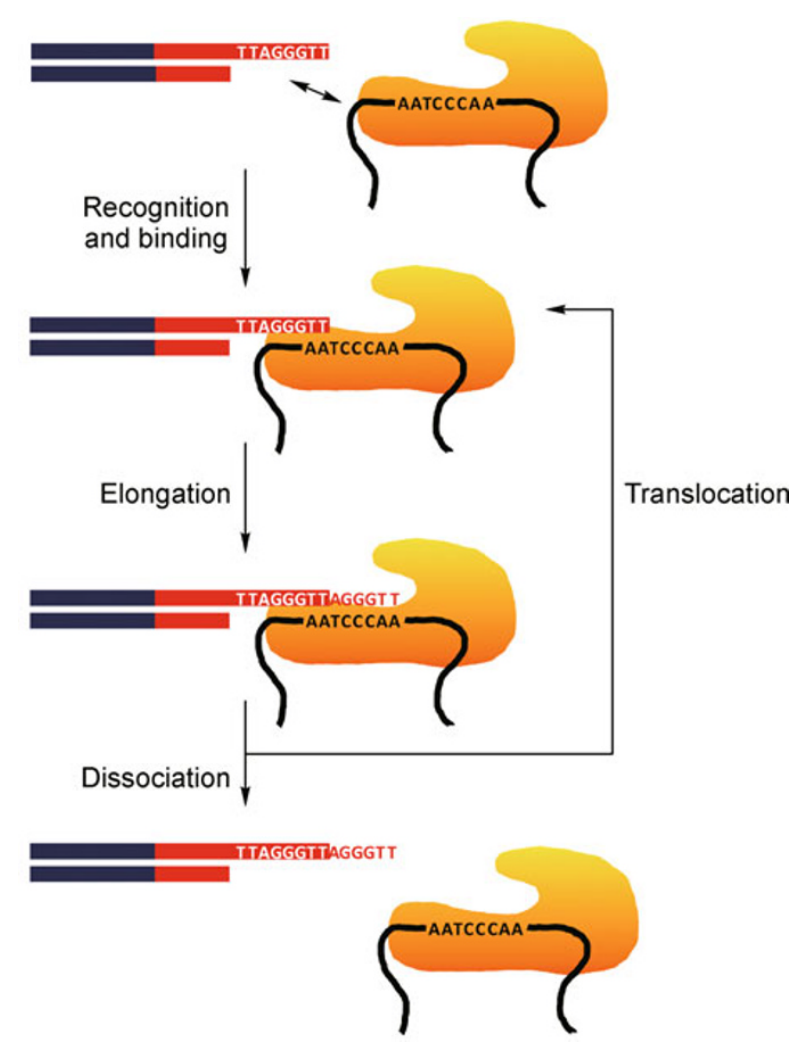

Figure 2. The telomerase reaction cycle. The telomerase reaction cycle consists of three distinct steps: substrate recognition and binding, where telomerase localises to the very $3^{\prime}$ terminus of the G-rich overhang; elongation, where telomeric repeats are added by TERT using TERC as a template; and dissociation or translocation, where telomerase moves to the new $3^{\prime}$ end of the chromosome to add another repeat, or releases the telomere.

to lengthen telomeres yet can facilitate anchorage-independent growth and tumor formation in xenograft mice (Stewart et al., 2002). A possible explanation for these observations is provided by the findings that ectopic expression of hTERT or mTERT alters the expression of a number of genes involved in growth and proliferation in human mammary epithelial cells or murine embryonic fibroblasts respectively (Smith et al., 2003; Geserick et al., 2006). The recent discovery of TERT as a component of a transcription regulation complex that binds chromatin and activates Wnt/ $\beta$-catenin target genes offers a mechanism that potentially explains these effects, and gives further support to the hypothesis that suggests extratelomeric roles for TERT/telomerase (Park et al., 2009). Intriguingly, inhibition of telomerase by ribozymes targeting hTERC down-regulates several key glycolytic genes and alters cellular morphology (Bagheri et al., 2006). This suggests that TERC alone or alternatively the active telomerase enzyme complex may be involved in the regulation of gene expression. Future work should investigate 


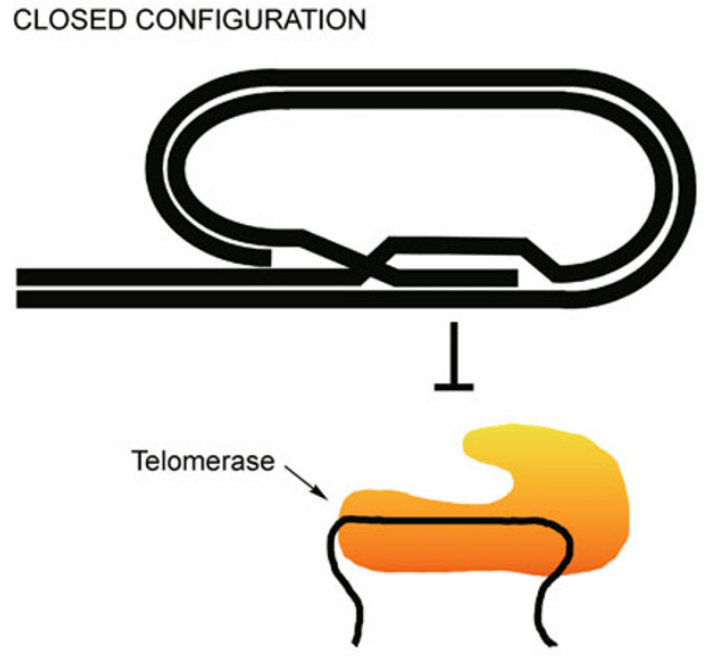

OPEN CONFIGURATION

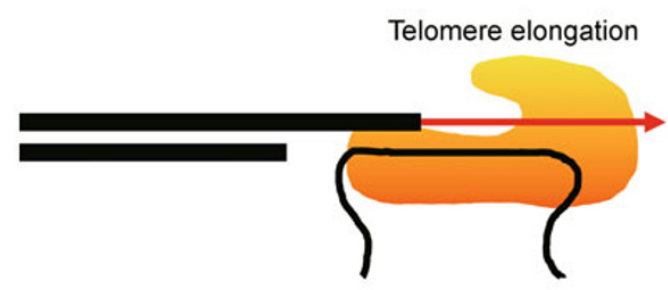

Figure 3. Telomerase exists in 'open' and 'closed' configurations. Telomeres can adopt at least two distinct structural conformations. The closed configuration of telomeres masks the $3^{\prime}$ end of the G-rich overhang and impairs telomerase access, preventing telomere lengthening. The open conformation facilitates the telomerase interaction with telomeres and allows for elongation.

whether telomerase or its constituents are involved in any additional transcriptional complexes or other mechanisms of gene regulation.

\section{REGULATION OF TELOMERASE}

Since TERT is the major factor in allowing for telomerase activity, it follows that its regulation is tightly controlled. Regulation of TERT is achieved at many levels, with gene expression, alternative splicing, protein folding, post-translational modification and interaction partners all influencing the expression and activity of TERT (Liu et al., 2010). The following will refer to the regulation of TERT in humans unless otherwise stated.

\section{Regulation of the TERT gene promoter}

As expression of exogenous hTERT is sufficient to recon- stitute telomerase activity in many otherwise telomerasenegative cells, it follows that transcriptional repression of the hTERT gene is the principal method by which telomerase is suppressed in normal differentiated cells. Regulation of the hTERT gene occurs at two general levels: firstly, the gene locus is in a condensed nuclease-resistant chromatin structure that restricts access to transcription factors and polymerases (Wang and Zhu, 2004); and secondly, a variety of these transcription factors can act on the proximal promoter region to influence gene expression. These regulatory mechanisms are discussed below.

Initial cloning of hTERT promoter yielded much information about the mechanisms underlying hTERT transcriptional regulation (Cong et al., 1999; Horikawa et al., 1999; Takakura et al., 1999). These studies identified an approximately 330 bp GC rich region upstream of the transcriptional start site as the hTERT core promoter, with additional important regulatory sites both further upstream and in the first and second exons. The variety of transcription factor binding sites found within the promoter reflects the complexity of hTERT gene regulation, with sites for c-Myc, Smad3, Sp1, Ap2, ETS and others all present (Fig. 4). These transcription regulators are the effectors of a broad range of cellular signaling pathways, enabling hTERT and telomerase activity to be regulated in response to a variety of stimuli.

The proto-oncogene c-Myc regulates a variety of genes implicated in cell growth, proliferation, apoptosis and metabolism (Dang, 1999). Several studies have demonstrated that c-Myc increases hTERT expression, and that a specific E-box motif (CACGTG, see Fig. 4) in the hTERT promoter mediates this up-regulation (Wang et al., 1998; Greenberg et al., 1999; Wu et al., 1999). Rapidly proliferating cells often contain high levels of c-Myc, and up-regulation of c-Myc is implicated in a wide variety of cancers (Nesbit et al., 1999). Furthermore, the c-Myc antagonist Mad has been shown to represses hTERT expression (Günes et al., 2000; Oh et al., 2000). Consistently, DMSO-induced differentiation of HL60 leukemia cells causes a gradual decrease in c-Myc and hTERT levels with a concordant increase in Mad (Xu et al., 2001). Therefore c-Myc is a key driving force behind sustained hTERT expression in cancer.

The Sp1 transcription factor stimulates hTERT expression through binding of the hTERT promoter at several GC boxes, with gene reporter assays determining that these sites are critically required for hTERT expression (Kyo et al., 2000). This enhancement of hTERT transcription by Sp1 occurs in co-operation with c-Myc, through the binding of a GC box adjacent to the E-box in the hTERT promoter (Kyo et al., 2000).

The Ets family of transcription factors is often deregulated in human cancers and Ets2 has been shown to stimulate hTERT expression via direct promoter binding and interaction with c-Myc (Seth and Watson, 2005; Xu et al., 2008). E2F-1 also enhances hTERT expression via direct promoter binding 


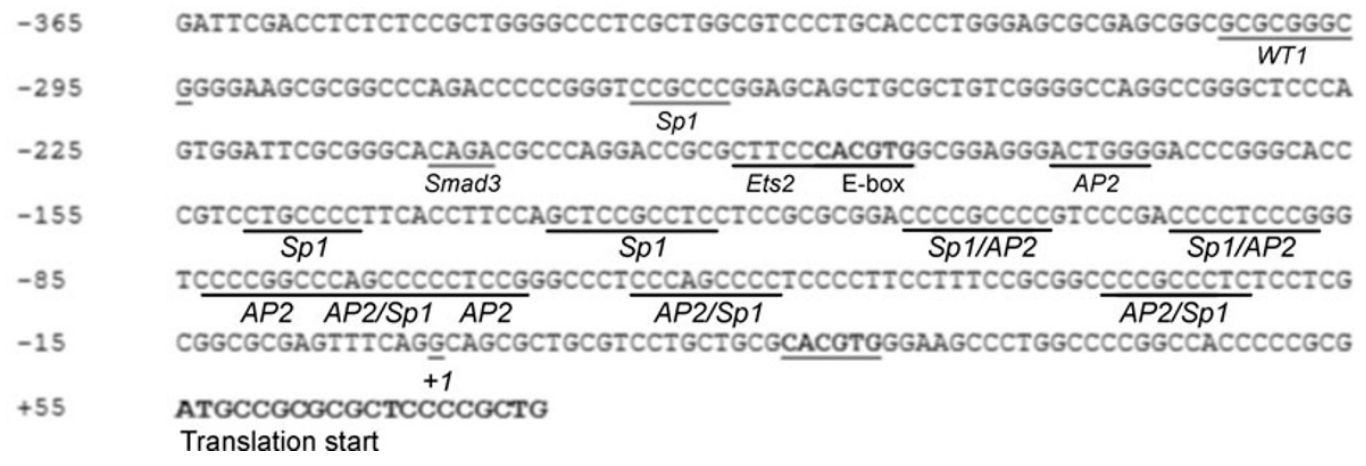

Figure 4. Organization of the hTERT core promoter region. The hTERT core promoter region extends approximately $330 \mathrm{bp}$ upstream from the transcription start site and contains binding sites for a variety of transcription factors, including Specificity Protein 1, Activator Protein 2, Wilms Tumor Protein 1, Ets, c-Myc (E-boxes) and Smads.

in normal somatic cells but inhibits hTERT transcription by disrupting Sp1 signaling in tumor cells (Won et al., 2002a). In addition, chromosome transfer studies indicate that hTERT repressors are located on human chromosomes 3 and 5 (Horikawa et al., 1998; Cuthbert et al., 1999; Kugoh et al., 2003).

\section{Regulation of the hTERT gene by epigenetic mechanisms}

Promoter hypermethylation is typically associated with gene repression. However, despite a high methylation potential due to its high GC content, initial studies failed to reveal a correlation between gene expression and methylation of the hTERT promoter in a variety of cancerous and immortalized cell lines (Devereux et al., 1999; Dessain et al., 2000). Nevertheless, treatment of human teratocarcinoma cells possessing a highly methylated hTERT promoter with the demethylating agent 5-azacytidine induced hTERT transcription and telomerase activity (Lopatina et al., 2003). This inconsistency has been resolved through a detailed analysis of hTERT promoter methylation in a variety of telomerase-positive cancer cell lines that determined all have little to no methylation in a specific small region immediately before the transcription start site whilst having varied methylation patterns in upstream promoter regions (Zinn et al., 2007).

The histone deacetylase inhibitor tricostatin A (TSA) has been shown to activate hTERT transcription in normal cells but not cancer cells, suggesting histone deacetylation represses hTERT in differentiated cells (Takakura et al., 2001). Interestingly, mutational analysis of the hTERT promoter demonstrated that the activation of hTERT transcription induced by TSA is dependent on Sp1 sites, but not E-boxes (Won et al., 2002b). This implies a role for Sp1 in the repression of hTERT, contrasting with its usually ascribed role as a transcriptional activator of hTERT in cancer.

\section{Alternative splicing of the hTERT gene}

Alternative splicing of hTERT may also regulate telomerase. In addition to the wild type mRNA species, three deletion variants are commonly identified: $h$ TERT $\alpha-\beta+$ which contains a 36 bp deletion in the reverse transcriptase coding region; hTERT $\alpha+\beta$ - containing a 182 bp deletion causing premature termination of translation; and hTERT $\alpha-\beta$ - which harbors both deletions (Ulaner et al., 1998). These deletion variants do not give rise to functional hTERT protein. Developing human embryos display tissue-specific expression and splicing patterns of hTERT (Ulaner et al., 2001). However, a survey of various cell lines found surprisingly little variation in the proportions of transcript variants expressed despite differences in cell origin, differentiation state and telomerase activity levels (Yi et al., 2001). Interestingly, while hTERT $\alpha+\beta$ + is the sole transcript that gives rise to functional hTERT protein, it commonly accounts for only $\sim 5 \%$ total hTERT mRNA, with inactive variants comprising the rest (Yi et al., 2001). As ectopic expression of hTERTa- $\beta+$ results in dominant-negative inhibition of telomerase activity (Colgin et al., 2000), hTERT deletion variants likely play a role in negatively regulating telomerase.

\section{Regulation of telomerase protein folding and assembly}

The chaperone proteins p23 and hsp90 are required for the effective assembly of the telomerase holoenzyme (Holt et al., 1999). In addition, both hsp90 and p23 remain associated with the telomerase holoenzyme complex and are required for efficient telomerase activity, suggesting a role beyond simple protein folding for these chaperones (Akalin et al., 2001; Forsythe et al., 2001). More recent findings support this idea, with the yeast homologs of hsp90 and p23 found to be integral in modulating the interaction of telomerase with DNA (Toogun et al., 2007; Toogun et al., 2008). 


\section{Post-translational modifications of hTERT}

Phosphorylation of hTERT by the serine/threonine kinases protein kinase $\mathrm{C}$ (PKC) and Akt has been shown to activate and enhance telomerase enzyme activity. Catalytic hTERT is a direct target of $\mathrm{PKCa}$ and $\mathrm{PKC} \zeta$ in breast and prostate cancer cell lines respectively, with phosphorylation promoting stability of the telomerase holoenzyme complex ( $\mathrm{Li}$ et al., 1998; Yu et al., 2001; Chang et al., 2006). Akt-a downstream kinase of the phosphoinositide-3 kinase pathway-is also a positive regulator of telomerase activity, demonstrated by pretreating cell lysates with recombinant Akt before measuring telomerase activity (Kang et al., 1999). Furthermore, antiphospho-Akt-substrate antibodies detect an increase in phosphorylation of hTERT immunoprecipitated from cells in which Akt has been stimulated (Kimura et al., 2004). However, while hTERT is a direct target of Akt and hTERT peptides bearing putative Akt consensus motifs can be phosphorylated, mutation of these sites in exogenously expressed hTERT does not alter telomerase activity (Kang et al., 1999; Kimura et al., 2004; Li et al., 2005). Therefore, direct phosphorylation of hTERT may not mediate the increase in telomerase activity induced by Akt, rather an indirect mechanism be responsible.

\section{Regulation of telomerase by interactive proteins}

In addition to proteins found within the telomerase holoenzyme complex (Pinto et al., 2011), several other proteinprotein interactions have been implicated in the regulation of telomerase activity. Recruitment of telomerase to the telomere requires the shelterin component TPP1, and recent findings describe a direct interaction between TPP1 and the TEN domain of hTERT enhances telomerase activity (Xin et al., 2007; Zaug et al., 2010). Ku70/80 also interacts with hTERT and may regulate the access of telomerase to telomere ends (Chai et al., 2002). Furthermore, PML-IV has been shown to negatively regulate telomerase activity in vivo by direct binding and recruitment of hTERT to PML bodies (Oh et al., 2009).

\section{CONCLUSION}

Recent years have seen significant progress made in understanding the regulation of telomerase activity and its role in telomere homeostasis during aging. New evidence from a wide range of approaches demonstrates that the regulation of telomerase is multifaceted, with many different molecular entities including intracellular signaling pathways, extracellular hormones and interacting proteins involved. As we have described, there exists a number of interfaces that represent potential targets for the modulation of telomerase activity that could both positively and negatively regulate the cell aging process. Future studies on cellular control mechanisms of the telomerase-mediated regulation of telomeres will translate into better clinical approaches to cellular aging and rejuvenation.

\section{ACKNOWLEDGEMENTS}

This work was supported by grants from the National Health and Medical Research Council of Australia, Cancer Council of Victoria, Australia, and the National Basic Research Program of China (Grant No. 2012CB911200). C.N. is a recipient of Monash Postgraduate Scholarship.

\section{ABBREVIATIONS}

ATM, ataxia-telangiectasia mutated; ATR, ataxia telangiectasia and Rad3-related; CTE, the C-terminal extension domain; PKC, protein kinase C; RT, the reverse transcriptase domain; TEN, telomerase essential $\mathrm{N}$-terminal domain; TERT, telomerase reverse transcriptase; TRB, the TERT RNA binding domain

\section{REFERENCES}

Akalin, A., Elmore, L.W., Forsythe, H.L., Amaker, B.A., McCollum, E. D., Nelson, P.S., Ware, J.L., and Holt, S.E. (2001). A novel mechanism for chaperone-mediated telomerase regulation during prostate cancer progression. Cancer Res 61, 4791-4796.

Allsopp, R.C., Vaziri, H., Patterson, C., Goldstein, S., Younglai, E.V., Futcher, A.B., Greider, C.W., and Harley, C.B. (1992). Telomere length predicts replicative capacity of human fibroblasts. Proc Natl Acad Sci U S A 89, 10114-10118.

Armanios, M. (2009). Syndromes of Telomere Shortening. Annu Rev Genomics Hum Genet 10, 45-61.

Armbruster, B.N., Banik, S.S., Guo, C., Smith, A.C., and Counter, C. M. (2001). N-terminal domains of the human telomerase catalytic subunit required for enzyme activity in vivo. Mol Cell Biol 21, 7775-7786.

Atzmon, G., Cho, M., Cawthon, R.M., Budagov, T., Katz, M., Yang, X., Siegel, G., Bergman, A., Huffman, D.M., Schechter, C.B., et al. (2010). Evolution in health and medicine Sackler colloquium: Genetic variation in human telomerase is associated with telomere length in Ashkenazi centenarians. Proc Natl Acad Sci U S A 107, 1710-1717.

Autexier, C., Pruzan, R., Funk, W.D., and Greider, C.W. (1996). Reconstitution of human telomerase activity and identification of a minimal functional region of the human telomerase RNA. EMBO $J$ 15, 5928-5935.

Ayouaz, A., Raynaud, C., Heride, C., Revaud, D., and Sabatier, L. (2008). Telomeres: hallmarks of radiosensitivity. Biochimie 90, 60-72.

Bachand, F., and Autexier, C. (2001). Functional regions of human telomerase reverse transcriptase and human telomerase RNA required for telomerase activity and RNA-protein interactions. Mol Cell Biol 21, 1888-1897.

Bagheri, S., Nosrati, M., Li, S., Fong, S., Torabian, S., Rangel, J., Moore, D.H., Federman, S., Laposa, R.R., Baehner, F.L., et al. (2006). Genes and pathways downstream of telomerase in melanoma metastasis. Proc Natl Acad Sci U S A 103, $11306-11311$.

Banik, S.S., Guo, C., Smith, A.C., Margolis, S.S., Richardson, D.A., 
Tirado, C.A., and Counter, C.M. (2002). C-terminal regions of the human telomerase catalytic subunit essential for in vivo enzyme activity. Mol Cell Biol 22, 6234-6246.

Banks, W.A., Morley, J.E., Farr, S.A., Price, T.O., Ercal, N., Vidaurre, I., and Schally, A.V. (2010). Effects of a growth hormone-releasing hormone antagonist on telomerase activity, oxidative stress, longevity, and aging in mice. Proc Natl Acad Sci U S A 107, 22272-22277.

Bayne, S., Jones, M.E., Li, H., Pinto, A.R., Simpson, E.R., and Liu, J. P. (2008). Estrogen deficiency leads to telomerase inhibition, telomere shortening and reduced cell proliferation in the adrenal gland of mice. Cell Res 18, 1141-1150.

Bayne, S., Li, H., Jones, M.E., Pinto, A.R., van Sinderen, M., Drummond, A., Simpson, E.R., and Liu, J.P. (2011). Estrogen deficiency reversibly induces telomere shortening in mouse granulosa cells and ovarian aging in vivo. Protein Cell 2, 333-346.

Britt, K.L., Drummond, A.E., Dyson, M., Wreford, N.G., Jones, M.E., Simpson, E.R., and Findlay, J.K. (2001). The ovarian phenotype of the aromatase knockout (ArKO) mouse. J Steroid Biochem Mol Biol 79, 181-185.

Britt, K.L., Kerr, J., O'Donnell, L., Jones, M.E., Drummond, A.E., Davis, S.R., Simpson, E.R., and Findlay, J.K. (2002). Estrogen regulates development of the somatic cell phenotype in the eutherian ovary. FASEB J 16, 1389-1397.

Browner, W.S., Kahn, A.J., Ziv, E., Reiner, A.P., Oshima, J., Cawthon, R.M., Hsueh, W.C., and Cummings, S.R. (2004). The genetics of human longevity. Am J Med 117, 851-860.

Bryan, T.M., Goodrich, K.J., and Cech, T.R. (2000). Telomerase RNA bound by protein motifs specific to telomerase reverse transcriptase. Mol Cell 6, 493-499.

Calado, R.T., and Young, N.S. (2009). Telomere diseases. N Engl J Med 361, 2353-2365.

Cassar, L., Li, H., Pinto, A.R., Nicholls, C., Bayne, S., and Liu, J.P. (2008). Bone morphogenetic protein-7 inhibits telomerase activity, telomere maintenance, and cervical tumor growth. Cancer Res 68, 9157-9166.

Cha, Y., Kwon, S.J., Seol, W., and Park, K.S. (2008). Estrogen receptor-alpha mediates the effects of estradiol on telomerase activity in human mesenchymal stem cells. Mol Cells 26, 454 458.

Chai, W., Ford, L.P., Lenertz, L., Wright, W.E., and Shay, J.W. (2002). Human Ku70/80 associates physically with telomerase through interaction with hTERT. J Biol Chem 277, 47242-47247.

Chang, J.T., Lu, Y.C., Chen, Y.J., Tseng, C.P., Chen, Y.L., Fang, C.W., and Cheng, A.J. (2006). hTERT phosphorylation by PKC is essential for telomerase holoprotein integrity and enzyme activity in head neck cancer cells. Br J Cancer 94, 870-878.

Chen, J.L., Blasco, M.A., and Greider, C.W. (2000). Secondary structure of vertebrate telomerase RNA. Cell 100, 503-514.

Cohen, S.B., Graham, M.E., Lovrecz, G.O., Bache, N., Robinson, P. J., and Reddel, R.R. (2007). Protein composition of catalytically active human telomerase from immortal cells. Science 315 , 1850-1853.

Colgin, L.M., Wilkinson, C., Englezou, A., Kilian, A., Robinson, M.O., and Reddel, R.R. (2000). The hTERTalpha splice variant is a dominant negative inhibitor of telomerase activity. Neoplasia 2, 426- 432.

Collins, K. (2006). The biogenesis and regulation of telomerase holoenzymes. Nat Rev Mol Cell Biol 7, 484-494.
Cong, Y.S., Wen, J., and Bacchetti, S. (1999). The human telomerase catalytic subunit hTERT: organization of the gene and characterization of the promoter. Hum Mol Genet 8, 137-142.

Counter, C.M., Meyerson, M., Eaton, E.N., Ellisen, L.W., Caddle, S. D., Haber, D.A., and Weinberg, R.A. (1998). Telomerase activity is restored in human cells by ectopic expression of hTERT (hEST2), the catalytic subunit of telomerase. Oncogene 16, 1217-1222.

Cuthbert, A.P., Bond, J., Trott, D.A., Gill, S., Broni, J., Marriott, A., Khoudoli, G., Parkinson, E.K., Cooper, C.S., and Newbold, R.F. (1999). Telomerase repressor sequences on chromosome 3 and induction of permanent growth arrest in human breast cancer cells. J Natl Cancer Inst 91, 37-45.

Dallaire, F., Dupuis, S., Fiset, S., and Chabot, B. (2000). Heterogeneous nuclear ribonucleoprotein A1 and UP1 protect mammalian telomeric repeats and modulate telomere replication in vitro. $\mathrm{J}$ Biol Chem 275, 14509-14516.

Dang, C.V. (1999). c-Myc target genes involved in cell growth, apoptosis, and metabolism. Mol Cell Biol 19, 1-11.

de Lange, T. (2009). How telomeres solve the end-protection problem. Science 326, 948-952.

Denchi, E.L. (2009). Give me a break: how telomeres suppress the DNA damage response. DNA Repair (Amst) 8, 1118-1126.

Dessain, S.K., Yu, H., Reddel, R.R., Beijersbergen, R.L., and Weinberg, R.A. (2000). Methylation of the human telomerase gene CpG island. Cancer Res 60, 537-541.

Devereux, T.R., Horikawa, I., Anna, C.H., Annab, L.A., Afshari, C.A., and Barrett, J.C. (1999). DNA methylation analysis of the promoter region of the human telomerase reverse transcriptase (hTERT) gene. Cancer Res 59, 6087-6090.

Feng, J., Funk, W.D., Wang, S.S., Weinrich, S.L., Avilion, A.A., Chiu, C.P., Adams, R.R., Chang, E., Allsopp, R.C., Yu, J., et al. (1995). The RNA component of human telomerase. Science 269, 1236-1241.

Fiset, S., and Chabot, B. (2001). hnRNP A1 may interact simultaneously with telomeric DNA and the human telomerase RNA in vitro. Nucleic Acids Res 29, 2268-2275.

Fisher, C.R., Graves, K.H., Parlow, A.F., and Simpson, E.R. (1998). Characterization of mice deficient in aromatase (ArKO) because of targeted disruption of the cyp19 gene. Proc Natl Acad Sci U S A 95, 6965-6970.

Forsythe, H.L., Jarvis, J.L., Turner, J.W., Elmore, L.W., and Holt, S.E. (2001). Stable association of hsp90 and p23, but Not hsp70, with active human telomerase. J Biol Chem 276, 15571-15574.

Friedman, K.L., and Cech, T.R. (1999). Essential functions of aminoterminal domains in the yeast telomerase catalytic subunit revealed by selection for viable mutants. Genes Dev 13, 2863-2874.

Geserick, C., Tejera, A., González-Suárez, E., Klatt, P., and Blasco, M.A. (2006). Expression of mTert in primary murine cells links the growth-promoting effects of telomerase to transforming growth factor-beta signaling. Oncogene 25, 4310-4319.

Gillis, A.J., Schuller, A.P., and Skordalakes, E. (2008). Structure of the Tribolium castaneum telomerase catalytic subunit TERT. Nature 455, 633-637.

González-Suárez, E., Geserick, C., Flores, J.M., and Blasco, M.A. (2005). Antagonistic effects of telomerase on cancer and aging in K5-mTert transgenic mice. Oncogene 24, 2256-2270.

González-Suárez, E., Samper, E., Ramírez, A., Flores, J.M., Martín- 
Caballero, J., Jorcano, J.L., and Blasco, M.A. (2001). Increased epidermal tumors and increased skin wound healing in transgenic mice overexpressing the catalytic subunit of telomerase, mTERT, in basal keratinocytes. EMBO J 20, 2619-2630.

Grasselli, A., Nanni, S., Colussi, C., Aiello, A., Benvenuti, V., Ragone, G., Moretti, F., Sacchi, A., Bacchetti, S., Gaetano, C., et al. (2008). Estrogen receptor-alpha and endothelial nitric oxide synthase nuclear complex regulates transcription of human telomerase. Circ Res 103, 34-42.

Greenberg, R.A., O'Hagan, R.C., Deng, H., Xiao, Q., Hann, S.R., Adams, R.R., Lichtsteiner, S., Chin, L., Morin, G.B., and DePinho, R.A. (1999). Telomerase reverse transcriptase gene is a direct target of c-Myc but is not functionally equivalent in cellular transformation. Oncogene 18, 1219-1226.

Greider, C.W., and Blackburn, E.H. (1985). Identification of a specific telomere terminal transferase activity in Tetrahymena extracts. Cell 43, 405-413.

Greider, C.W., and Blackburn, E.H. (1987). The telomere terminal transferase of Tetrahymena is a ribonucleoprotein enzyme with two kinds of primer specificity. Cell 51, 887-898.

Günes, C., Lichtsteiner, S., Vasserot, A.P., and Englert, C. (2000). Expression of the hTERT gene is regulated at the level of transcriptional initiation and repressed by Mad1. Cancer Res 60, 2116-2121.

Guo, C., Armbruster, B.N., Price, D.T., and Counter, C.M. (2003). In vivo regulation of $\mathrm{hTERT}$ expression and telomerase activity by androgen. J Urol 170, 615-618.

Hahn, W.C., Stewart, S.A., Brooks, M.W., York, S.G., Eaton, E., Kurachi, A., Beijersbergen, R.L., Knoll, J.H., Meyerson, M., and Weinberg, R.A. (1999). Inhibition of telomerase limits the growth of human cancer cells. Nat Med 5, 1164-1170.

Harley, C.B. (1991). Telomere loss: mitotic clock or genetic time bomb? Mutat Res 256, 271-282.

Harley, C.B. (2008). Telomerase and cancer therapeutics. Nat Rev Cancer 8, 167-179.

Heiss, N.S., Knight, S.W., Vulliamy, T.J., Klauck, S.M., Wiemann, S., Mason, P.J., Poustka, A., and Dokal, I. (1998). X-linked dyskeratosis congenita is caused by mutations in a highly conserved gene with putative nucleolar functions. Nat Genet 19, 32-38.

Herbert, B., Pitts, A.E., Baker, S.I., Hamilton, S.E., Wright, W.E., Shay, J.W., and Corey, D.R. (1999). Inhibition of human telomerase in immortal human cells leads to progressive telomere shortening and cell death. Proc Natl Acad Sci U S A 96, 14276-14281.

Herrera, E., Samper, E., and Blasco, M.A. (1999). Telomere shortening in mTR-/- embryos is associated with failure to close the neural tube. EMBO J 18, 1172-1181.

Holt, S.E., Aisner, D.L., Baur, J., Tesmer, V.M., Dy, M., Ouellette, M., Trager, J.B., Morin, G.B., Toft, D.O., Shay, J.W., et al. (1999). Functional requirement of p23 and Hsp90 in telomerase complexes. Genes Dev 13, 817-826.

Horikawa, I., Cable, P.L., Afshari, C., and Barrett, J.C. (1999). Cloning and characterization of the promoter region of human telomerase reverse transcriptase gene. Cancer Res 59, 826-830.

Horikawa, I., Oshimura, M., and Barrett, J.C. (1998). Repression of the telomerase catalytic subunit by a gene on human chromosome 3 that induces cellular senescence. Mol Carcinog 22, 65-72.

Huard, S., Moriarty, T.J., and Autexier, C. (2003). The C terminus of the human telomerase reverse transcriptase is a determinant of enzyme processivity. Nucleic Acids Res 31, 4059- 4070.

Jacobs, S.A., Podell, E.R., and Cech, T.R. (2006). Crystal structure of the essential $\mathrm{N}$-terminal domain of telomerase reverse transcriptase. Nat Struct Mol Biol 13, 218-225.

Jaskelioff, M., Muller, F.L., Paik, J.H., Thomas, E., Jiang, S., Adams, A.C., Sahin, E., Kost-Alimova, M., Protopopov, A., Cadiñanos, J., et al. (2011). Telomerase reactivation reverses tissue degeneration in aged telomerase-deficient mice. Nature 469, 102-106.

Kalantaridou, S.N., Naka, K.K., Bechlioulis, A., Makrigiannakis, A., Michalis, L., and Chrousos, G.P. (2006). Premature ovarian failure, endothelial dysfunction and estrogen-progestogen replacement. Trends Endocrinol Metab 17, 101-109.

Kang, S.S., Kwon, T., Kwon, D.Y., and Do, S.I. (1999). Akt protein kinase enhances human telomerase activity through phosphorylation of telomerase reverse transcriptase subunit. J Biol Chem 274, 13085-13090.

Kelleher, C., Teixeira, M.T., Förstemann, K., and Lingner, J. (2002). Telomerase: biochemical considerations for enzyme and substrate. Trends Biochem Sci 27, 572-579.

Kiaris, H., and Schally, A.V. (1999). Decrease in telomerase activity in U-87MG human glioblastomas after treatment with an antagonist of growth hormone-releasing hormone. Proc Natl Acad Sci U S A 96, 226-231.

Kimura, A., Ohmichi, M., Kawagoe, J., Kyo, S., Mabuchi, S., Takahashi, T., Ohshima, C., Arimoto-Ishida, E., Nishio, Y., Inoue, M., et al. (2004). Induction of hTERT expression and phosphorylation by estrogen via Akt cascade in human ovarian cancer cell lines. Oncogene 23, 4505-4515.

Kimura, M., Barbieri, M., Gardner, J.P., Skurnick, J., Cao, X., van Riel, N., Rizzo, M.R., Paoliso, G., and Aviv, A. (2007). Leukocytes of exceptionally old persons display ultra-short telomeres. Am J Physiol Regul Integr Comp Physiol 293, R2210-R2217.

Kimura, M., Cherkas, L.F., Kato, B.S., Demissie, S., Hjelmborg, J.B., Brimacombe, M., Cupples, A., Hunkin, J.L., Gardner, J.P., Lu, X., et al. (2008). Offspring's leukocyte telomere length, paternal age, and telomere elongation in sperm. PLoS Genet 4, e37.

Kugoh, H., Shigenami, K., Funaki, K., Barrett, J.C., and Oshimura, M. (2003). Human chromosome 5 carries a putative telomerase repressor gene. Genes Chromosomes Cancer 36, 37-47.

Kyo, S., Takakura, M., Kanaya, T., Zhuo, W., Fujimoto, K., Nishio, Y., Orimo, A., and Inoue, M. (1999). Estrogen activates telomerase. Cancer Res 59, 5917-5921.

Kyo, S., Takakura, M., Taira, T., Kanaya, T., Itoh, H., Yutsudo, M., Ariga, H., and Inoue, M. (2000). Sp1 cooperates with c-Myc to activate transcription of the human telomerase reverse transcriptase gene (hTERT). Nucleic Acids Res 28, 669-677.

LaBranche, H., Dupuis, S., Ben-David, Y., Bani, M.R., Wellinger, R.J., and Chabot, B. (1998). Telomere elongation by hnRNP A1 and a derivative that interacts with telomeric repeats and telomerase. Nat Genet 19, 199-202.

Lai, C.K., Mitchell, J.R., and Collins, K. (2001). RNA binding domain of telomerase reverse transcriptase. Mol Cell Biol 21, 990-1000.

Laviolette, L.A., Garson, K., Macdonald, E.A., Senterman, M.K., Courville, K., Crane, C.A., and Vanderhyden, B.C. (2010). 17betaestradiol accelerates tumor onset and decreases survival in a transgenic mouse model of ovarian cancer. Endocrinology 151, 929-938. 
Lee, H.W., Blasco, M.A., Gottlieb, G.J., Horner, J.W. 2nd, Greider, C. W., and DePinho, R.A. (1998). Essential role of mouse telomerase in highly proliferative organs. Nature 392, 569-574.

Li, H., Pinto, A.R., Duan, W., Li, J., Toh, B.H., and Liu, J.P. (2005). Telomerase down-regulation does not mediate PC12 pheochromocytoma cell differentiation induced by NGF, but requires MAP kinase signalling. J Neurochem 95, 891-901.

Li, H., Zhao, L., Yang, Z., Funder, J.W., and Liu, J.P. (1998). Telomerase is controlled by protein kinase Calpha in human breast cancer cells. J Biol Chem 273, 33436-33442.

Lin, J., Kroenke, C.H., Epel, E., Kenna, H.A., Wolkowitz, O.M., Blackburn, E., and Rasgon, N.L. (2011). Greater endogenous estrogen exposure is associated with longer telomeres in postmenopausal women at risk for cognitive decline. Brain Res 1379, 224-231.

Ling, S., Zhou, L., Li, H., Dai, A., Liu, J.P., Komesaroff, P.A., and Sudhir, K. (2006). Effects of 17beta-estradiol on growth and apoptosis in human vascular endothelial cells: influence of mechanical strain and tumor necrosis factor-alpha. Steroids 71 , 799-808.

Liu, J.P., Chen, S.M., Cong, Y.S., Nicholls, C., Zhou, S.F., Tao, Z.Z., and Li, H. (2010). Regulation of telomerase activity by apparently opposing elements. Ageing Res Rev 9, 245-256.

Loayza, D., and De Lange, T. (2003). POT1 as a terminal transducer of TRF1 telomere length control. Nature 423, 1013-1018.

Lopatina, N.G., Poole, J.C., Saldanha, S.N., Hansen, N.J., Key, J.S., Pita, M.A., Andrews, L.G., and Tollefsbol, T.O. (2003). Control mechanisms in the regulation of telomerase reverse transcriptase expression in differentiating human teratocarcinoma cells. Biochem Biophys Res Commun 306, 650-659.

Martínez, P., Thanasoula, M., Muñoz, P., Liao, C., Tejera, A., McNees, C., Flores, J.M., Fernández-Capetillo, O., Tarsounas, M., and Blasco, M.A. (2009). Increased telomere fragility and fusions resulting from TRF1 deficiency lead to degenerative pathologies and increased cancer in mice. Genes Dev 23, 2060-2075.

McNees, C.J., Tejera, A.M., Martínez, P., Murga, M., Mulero, F., Fernandez-Capetillo, O., and Blasco, M.A. (2010). ATR suppresses telomere fragility and recombination but is dispensable for elongation of short telomeres by telomerase. J Cell Biol 188, 639-652.

Meeker, A.K., Sommerfeld, H.J., and Coffey, D.S. (1996). Telomerase is activated in the prostate and seminal vesicles of the castrated rat. Endocrinology 137, 5743-5746.

Misiti, S., Nanni, S., Fontemaggi, G., Cong, Y.S., Wen, J., Hirte, H.W., Piaggio, G., Sacchi, A., Pontecorvi, A., Bacchetti, S., et al. (2000). Induction of hTERT expression and telomerase activity by estrogens in human ovary epithelium cells. Mol Cell Biol 20, 3764-3771.

Mitchell, M., Gillis, A., Futahashi, M., Fujiwara, H., and Skordalakes, E. (2010). Structural basis for telomerase catalytic subunit TERT binding to RNA template and telomeric DNA. Nat Struct Mol Biol 17, 513-518.

Moehren, U., Papaioannou, M., Reeb, C.A., Grasselli, A., Nanni, S., Asim, M., Roell, D., Prade, I., Farsetti, A., and Baniahmad, A. (2008). Wild-type but not mutant androgen receptor inhibits expression of the hTERT telomerase subunit: a novel role of AR mutation for prostate cancer development. FASEB J 22, 1258-1267.
Murnane, J.P. (2010). Telomere loss as a mechanism for chromosome instability in human cancer. Cancer Res 70, 4255-4259.

Nakamura, T.M., Morin, G.B., Chapman, K.B., Weinrich, S.L., Andrews, W.H., Lingner, J., Harley, C.B., and Cech, T.R. (1997). Telomerase catalytic subunit homologs from fission yeast and human. Science 277, 955-959.

Nesbit, C.E., Tersak, J.M., and Prochownik, E.V. (1999). MYC oncogenes and human neoplastic disease. Oncogene 18, 3004-3016.

Njajou, O.T., Cawthon, R.M., Damcott, C.M., Wu, S.H., Ott, S., Garant, M.J., Blackburn, E.H., Mitchell, B.D., Shuldiner, A.R., and Hsueh, W.C. (2007). Telomere length is paternally inherited and is associated with parental lifespan. Proc Natl Acad Sci U S A 104, 12135-12139.

Njajou, O.T., Hsueh, W.C., Blackburn, E.H., Newman, A.B., Wu, S.H., Li, R., Simonsick, E.M., Harris, T.M., Cummings, S.R., and Cawthon, R.M., and the Health ABC study. (2009). Association between telomere length, specific causes of death, and years of healthy life in health, aging, and body composition, a populationbased cohort study. J Gerontol A Biol Sci Med Sci 64, 860-864.

Oh, S., Song, Y.H., Yim, J., and Kim, T.K. (2000). Identification of Mad as a repressor of the human telomerase (hTERT) gene. Oncogene 19, 1485-1490.

Oh, W., Ghim, J., Lee, E.W., Yang, M.R., Kim, E.T., Ahn, J.H., and Song, J. (2009). PML-IV functions as a negative regulator of telomerase by interacting with TERT. J Cell Sci 122, 2613-2622.

Ornish, D., Lin, J., Daubenmier, J., Weidner, G., Epel, E., Kemp, C., Magbanua, M.J., Marlin, R., Yglecias, L., Carroll, P.R., et al. (2008). Increased telomerase activity and comprehensive lifestyle changes: a pilot study. Lancet Oncol 9, 1048-1057.

Park, J.I., Venteicher, A.S., Hong, J.Y., Choi, J., Jun, S., Shkreli, M., Chang, W., Meng, Z., Cheung, P., Ji, H., et al. (2009). Telomerase modulates Wnt signalling by association with target gene chromatin. Nature 460, 66-72.

Peng, Y., Mian, I.S., and Lue, N.F. (2001). Analysis of telomerase processivity: mechanistic similarity to HIV-1 reverse transcriptase and role in telomere maintenance. Mol Cell 7, 1201-1211.

Pinto, A.R., Li, H., Nicholls, C., and Liu, J.P. (2011). Telomere protein complexes and interactions with telomerase in telomere maintenance. Front Biosci 16, 187-207.

Ramírez, R., Carracedo, J., Jiménez, R., Canela, A., Herrera, E., Aljama, P., and Blasco, M.A. (2003). Massive telomere loss is an early event of DNA damage-induced apoptosis. J Biol Chem 278, 836-842.

Ravindranath, N., loffe, S.L., Marshall, G.R., Ramaswamy, S., Plant, T.M., and Dym, M. (2001). Androgen depletion activates telomerase in the prostate of the nonhuman primate, Macaca mulatta. Prostate 49, 79-89.

Rochette, P.J., and Brash, D.E. (2010). Human telomeres are hypersensitive to UV-induced DNA Damage and refractory to repair. PLoS Genet 6, e1000926.

Rudolph, K.L., Chang, S., Lee, H.W., Blasco, M., Gottlieb, G.J., Greider, C., and DePinho, R.A. (1999). Longevity, stress response, and cancer in aging telomerase-deficient mice. Cell 96, 701-712.

Seimiya, H., Sawada, H., Muramatsu, Y., Shimizu, M., Ohko, K., Yamane, K., and Tsuruo, T. (2000). Involvement of 14-3-3 proteins in nuclear localization of telomerase. EMBO J 19, 2652-2661.

Seth, A., and Watson, D.K. (2005). ETS transcription factors and their 
emerging roles in human cancer. Eur J Cancer 41, 2462-2478.

Sfeir, A., Kosiyatrakul, S.T., Hockemeyer, D., MacRae, S.L., Karlseder, J., Schildkraut, C.L., and de Lange, T. (2009). Mammalian telomeres resemble fragile sites and require TRF1 for efficient replication. Cell 138, 90-103.

Sharma, H.W., Sokoloski, J.A., Perez, J.R., Maltese, J.Y., Sartorelli, A.C., Stein, C.A., Nichols, G., Khaled, Z., Telang, N.T., and Narayanan, R. (1995). Differentiation of immortal cells inhibits telomerase activity. Proc Natl Acad Sci U S A 92, 12343-12346.

Shay, J.W., and Bacchetti, S. (1997). A survey of telomerase activity in human cancer. Eur J Cancer 33, 787-791.

Smith, L.L., Coller, H.A., and Roberts, J.M. (2003). Telomerase modulates expression of growth-controlling genes and enhances cell proliferation. Nat Cell Biol 5, 474-479.

Soda, H., Raymond, E., Sharma, S., Lawrence, R., Davidson, K., Oka, M., Kohno, S., Izbicka, E., and Von Hoff, D.D. (2000). Effects of androgens on telomerase activity in normal and malignant prostate cells in vitro. Prostate 43, 161-168.

Stewart, S.A., Hahn, W.C., O'Connor, B.F., Banner, E.N., Lundberg, A.S., Modha, P., Mizuno, H., Brooks, M.W., Fleming, M., Zimonjic, D.B., et al. (2002). Telomerase contributes to tumorigenesis by a telomere length-independent mechanism. Proc Natl Acad Sci U S A 99, 12606-12611.

Takakura, M., Kyo, S., Kanaya, T., Hirano, H., Takeda, J., Yutsudo, M., and Inoue, M. (1999). Cloning of human telomerase catalytic subunit (hTERT) gene promoter and identification of proximal core promoter sequences essential for transcriptional activation in immortalized and cancer cells. Cancer Res 59, 551-557.

Takakura, M., Kyo, S., Sowa, Y., Wang, Z., Yatabe, N., Maida, Y., Tanaka, M., and Inoue, M. (2001). Telomerase activation by histone deacetylase inhibitor in normal cells. Nucleic Acids Res 29, 3006-3011.

Tang, L., and Sawers, R.S. (1989). Twin pregnancy in premature ovarian failure after estrogen treatment: a case report. Am J Obstet Gynecol 161, 172-173.

Teixeira, M.T., Arneric, M., Sperisen, P., and Lingner, J. (2004). Telomere length homeostasis is achieved via a switch between telomerase- extendible and -nonextendible states. Cell 117, 323-335.

Terry, D.F., Nolan, V.G., Andersen, S.L., Perls, T.T., and Cawthon, R. (2008). Association of longer telomeres with better health in centenarians. J Gerontol A Biol Sci Med Sci 63, 809-812.

Theimer, C.A., and Feigon, J. (2006). Structure and function of telomerase RNA. Curr Opin Struct Biol 16, 307-318.

Ting, N.S., Pohorelic, B., Yu, Y., Lees-Miller, S.P., and Beattie, T.L. (2009). The human telomerase RNA component, hTR, activates the DNA-dependent protein kinase to phosphorylate heterogeneous nuclear ribonucleoprotein A1. Nucleic Acids Res 37, 6105-6115.

Ting, N.S., Yu, Y., Pohorelic, B., Lees-Miller, S.P., and Beattie, T.L. (2005). Human Ku70/80 interacts directly with hTR, the RNA component of human telomerase. Nucleic Acids Res 33, 2090-2098.

Tomás-Loba, A., Flores, I., Fernández-Marcos, P.J., Cayuela, M.L., Maraver, A., Tejera, A., Borrás, C., Matheu, A., Klatt, P., Flores, J. M., et al. (2008). Telomerase reverse transcriptase delays aging in cancer-resistant mice. Cell 135, 609-622.

Toogun, O.A., Dezwaan, D.C., and Freeman, B.C. (2008). The hsp90 molecular chaperone modulates multiple telomerase activities. Mol Cell Biol 28, 457-467.

Toogun, O.A., Zeiger, W., and Freeman, B.C. (2007). The p23 molecular chaperone promotes functional telomerase complexes through DNA dissociation. Proc Natl Acad Sci U S A 104, 5765-5770.

Ulaner, G.A., Hu, J.F., Vu, T.H., Giudice, L.C., and Hoffman, A.R. (1998). Telomerase activity in human development is regulated by human telomerase reverse transcriptase (hTERT) transcription and by alternate splicing of hTERT transcripts. Cancer Res 58, 4168-4172.

Ulaner, G.A., Hu, J.F., Vu, T.H., Giudice, L.C., and Hoffman, A.R. (2001). Tissue-specific alternate splicing of human telomerase reverse transcriptase ( $h T E R T$ ) influences telomere lengths during human development. Int J Cancer 91, 644-649.

Verdun, R.E., and Karlseder, J. (2006). The DNA damage machinery and homologous recombination pathway act consecutively to protect human telomeres. Cell 127, 709-720.

Wang, J., Xie, L.Y., Allan, S., Beach, D., and Hannon, G.J. (1998). Myc activates telomerase. Genes Dev 12, 1769-1774.

Wang, S., and Zhu, J. (2004). The hTERT gene is embedded in a nuclease-resistant chromatin domain. J Biol Chem 279, 55401-55410.

Won, J., Yim, J., and Kim, T.K. (2002a). Opposing regulatory roles of E2F in human telomerase reverse transcriptase (hTERT) gene expression in human tumor and normal somatic cells. FASEB J 16 , 1943-1945.

Won, J., Yim, J., and Kim, T.K. (2002b). Sp1 and Sp3 recruit histone deacetylase to repress transcription of human telomerase reverse transcriptase (hTERT) promoter in normal human somatic cells. J Biol Chem 277, 38230-38238.

Wong, J.M., and Collins, K. (2003). Telomere maintenance and disease. Lancet 362, 983-988.

Wu, K.J., Grandori, C., Amacker, M., Simon-Vermot, N., Polack, A., Lingner, J., and Dalla-Favera, R. (1999). Direct activation of TERT transcription by c-MYC. Nat Genet 21, 220-224.

Wymenga, L.F., Wisman, G.B., Veenstra, R., Ruiters, M.H., and Mensink, H.J. (2000). Telomerase activity in needle biopsies from prostate cancer and benign prostates. Eur J Clin Invest 30, 330-335.

Xia, J., Peng, Y., Mian, I.S., and Lue, N.F. (2000). Identification of functionally important domains in the $\mathrm{N}$-terminal region of telomerase reverse transcriptase. Mol Cell Biol 20, 5196-5207.

Xin, H., Liu, D., Wan, M., Safari, A., Kim, H., Sun, W., O'Connor, M.S., and Songyang, Z. (2007). TPP1 is a homologue of ciliate TEBPbeta and interacts with POT1 to recruit telomerase. Nature 445 , 559-562.

Xu, D., Dwyer, J., Li, H., Duan, W., and Liu, J.P. (2008). Ets2 maintains hTERT gene expression and breast cancer cell proliferation by interacting with c-Myc. J Biol Chem 283, 23567-23580.

Xu, D., Popov, N., Hou, M., Wang, Q., Björkholm, M., Gruber, A., Menkel, A.R., and Henriksson, M. (2001). Switch from Myc/Max to Mad1/Max binding and decrease in histone acetylation at the telomerase reverse transcriptase promoter during differentiation of HL60 cells. Proc Natl Acad Sci U S A 98, 3826-3831.

Yi, X., Shay, J.W., and Wright, W.E. (2001). Quantitation of telomerase components and hTERT mRNA splicing patterns in 
immortal human cells. Nucleic Acids Res 29, 4818 4825.

Yu, C.C., Lo, S.C., and Wang, T.C. (2001). Telomerase is regulated by protein kinase C-zeta in human nasopharyngeal cancer cells. Biochem J 355, 459-464.

Zaug, A.J., Podell, E.R., Nandakumar, J., and Cech, T.R. (2010). Functional interaction between telomere protein TPP1 and telomerase. Genes Dev 24, 613-622.

Zhang, Q.S., Manche, L., Xu, R.M., and Krainer, A.R. (2006). hnRNP A1 associates with telomere ends and stimulates telomerase activity. RNA 12, 1116-1128.

Zhang, W., Kapusta, L.R., Slingerland, J.M., and Klotz, L.H. (1998).
Telomerase activity in prostate cancer, prostatic intraepithelial neoplasia, and benign prostatic epithelium. Cancer Res 58, 619-621.

Zhang, X., Mar, V., Zhou, W., Harrington, L., and Robinson, M.O. (1999). Telomere shortening and apoptosis in telomerase-inhibited human tumor cells. Genes Dev 13, 2388-2399.

Zinn, R.L., Pruitt, K., Eguchi, S., Baylin, S.B., and Herman, J.G. (2007). hTERT is expressed in cancer cell lines despite promoter DNA methylation by preservation of unmethylated DNA and active chromatin around the transcription start site. Cancer Res 67, 194-201. 